\title{
Simulation of Rolling Contact Fatigue Strength for Traction Drive Elements*
}

\author{
Yukihito NARITA**, Masashi YAMANAKA***, Toshiharu KAZAMA**, \\ Yasuhiro OSAFUNE** and Tomoya MASUYAMA**** \\ **Muroran Institute of Technology, \\ 27-1 Mizumoto-cho, Muroran 050-8585, Japan \\ E-mail: y-narita@mmm.muroran-it.ac.jp \\ ***High Energy Accelerator Research Organization, \\ 1-1 Oho, Tsukuba, Ibaraki 305-0801, Japan \\ ****Tsuruoka National College of Technology, \\ 104 Inooka-sawada, Tsuruoka, Yamagata 997-8511, Japan
}

\begin{abstract}
A simulation of the rolling contact fatigue strength of a traction drive element was proposed. The simulation can account for both the distribution of sizes of inclusions in the element material and the influence of traction forces at the element surface. The shear strength of the matrix structure surrounding an inclusion was estimated with an equation. The hardness distribution and the Weibull distribution of inclusion dimensions, which were necessary parameters to calculate the rolling contact fatigue strength, were determined by observation of an actual test specimen. And the rolling contact fatigue strength was compared with the distribution of shear stresses in a roller affected by traction forces. A simulation assuming the same traction coefficient as that in the experiment predicted a rolling contact fatigue strength of $810 \mathrm{MPa}$ with a standard deviation of $39.2 \mathrm{MPa}$, which differed from the experimental value by only $2.5 \%$. Simulations of the rolling contact fatigue strength were then carried out while varying the traction coefficient. The contact force resulting in failure was observed to fall as the traction coefficient increased and the torque capacity increased. Thus, the torque capacity increases with the traction coefficient, regardless of changes in the rolling contact fatigue strength.
\end{abstract}

Key words: Machine Element, Traction Drive, Rolling Contact Fatigue, Inclusion, Tribology, Shear Stress

\section{Introduction}

A traction drive transmits power through shear forces in the elastohydrodynamic lubrication film between pairs of rollers. Traction drives have several advantages over gears, notably, lower vibration and noise, and capability in assembling continuously variable transmissions (CVT). Since contact forces play an integral role in traction drives for power transmission, high contact pressures arise at the points of contact between rollers. For example, toroidal CVTs for automobiles are operated at maximum Hertzian pressures exceeding $4 \mathrm{GPa}^{(1)}$. These high contact pressures cause failure through rolling contact fatigue, which occurs in bearings and gears. The most common mode of failure is flaking of the surface. Therefore, prediction of the rolling contact fatigue strength is essential during the design of a traction drive.

A number of studies have reported on the fatigue strength in traction drives. Many kinds of fatigue tests have been carried out on rollers and balls to examine the influence of

${ }^{*}$ Received 4 Mar., 2013 (No. 13-0115) [DOI: 10.1299/jamdsm.7.432]

Copyright $(\subseteq 2013$ by JSME 
failure mechanisms, operating conditions, lubrication modes, roller materials, etc., on fatigue strength $^{(2)(5)}$. Coy et al. ${ }^{(6)(7)}$ estimated the finite life region of a Nasvytis multiroller traction drive under the assumption of no fatigue limit by using the Lundenberg-Palmgren theory $^{(8)}$ to predict the bearing life. Their research suggested an internal fatigue failure model in which cracks initiate at inclusions and other originations of defects due to shear stresses within the material. However, that approach does not take into account the influence of defect size. Nikas proposed a fatigue life prediction model for a toroidal $\mathrm{CVT}^{(9)}$, but his model is based on a modified Lundberg-Palmgren model, which was improved by Ioannides et al. ${ }^{(10)}$. This model also does not take into account the influence of defect size. Murakami proposed an equation for predicting the fatigue limit, which considers the size of microdefects or inclusions ${ }^{(11)}$, and Yamanaka et al. extended Murakami's method and proposed a prediction equation for estimating the rolling contact fatigue strength of traction drive elements ${ }^{(12)}$.

It is well known that the high-strength materials employed in traction drives and gears show high scatter in fatigue strength ${ }^{(13)}$. A large number of fatigue tests must be performed to estimate such scatter. It would be very useful in the strength design if the scatter could be estimated by simulation. Masuyama et al. proposed a modification of Murakami's equation for estimating the bending fatigue strength of tooth roots in carburized gears based on hardness, residual stress, and inclusion size ${ }^{(14)}$. They constructed a simulation model of a gear containing distributed inclusions, simulated the bending fatigue strength, and showed that the predicted fatigue strength and scatter matched the experimental results ${ }^{(15)}$. Masuyama's approach was employed in this study to propose a simulation of the rolling contact fatigue strength of traction drive elements. In this paper, first the simulation procedure is described, followed by explanations of the simulated roller and the method for calculating the strength. Finally, the simulation results are compared with the experimental results to validate the simulation.

\section{Criterion of Rolling Contact Fatigue ${ }^{(12)}$}

During rolling contact fatigue, cracks propagate parallel to the rolling direction. Therefore, as in previous research, we concentrate on the shear stress parallel to the rolling direction, $\tau_{\mathrm{xz}}$. These cracks initiate from the inclusions and defects within the material and propagate to the point of failure by this $\tau_{\mathrm{xz}}$. This study uses the following criterion for the failure from a given defect in a traction drive element: rolling contact fatigue strength $\tau_{\mathrm{w}}$ is assumed around a defect, and failure is assumed to occur if the shear stress $\tau_{\mathrm{xz}}$ due to the contact force $F_{\mathrm{c}}$, which is normal to contact point, exceeds $\tau_{\mathrm{w}}$. The prediction equation for $\tau_{\mathrm{w}}$ is given below ${ }^{(12)}$ and is defined as the rolling contact fatigue strength for $10^{7}$ cycles:

$$
\tau_{w}=c \times \frac{1.56(H v+120)}{(\sqrt{\text { area }})^{1 / 6}}
$$

where $H v$ is the Vickers hardness and area is the projected area of an inclusion onto a plane perpendicular to the evaluation stress. Coefficient $c$ is assigned the value 0.97 on the basis of the rolling contact fatigue strength found in a preliminary experiment using rollers with artificially induced defects of determined dimensions. The details of the derivation of coefficient $c$ are presented in the appendix.

\section{Simulation Method}

\subsection{Simulation procedure}

The inclusion that ultimately causes failure must be identified, and its dimensions must 
be found in order to use Eq. (1) to estimate the rolling contact fatigue strength. This identification is extremely difficult. The purpose of this simulation is to make a simple calculation of the fatigue strength and scatter by using the parameters of an inclusion in the material, the roller shape, and the traction coefficient. Figure 1 is a flow chart of the proposed simulation of the rolling contact fatigue strength of the traction drive elements.

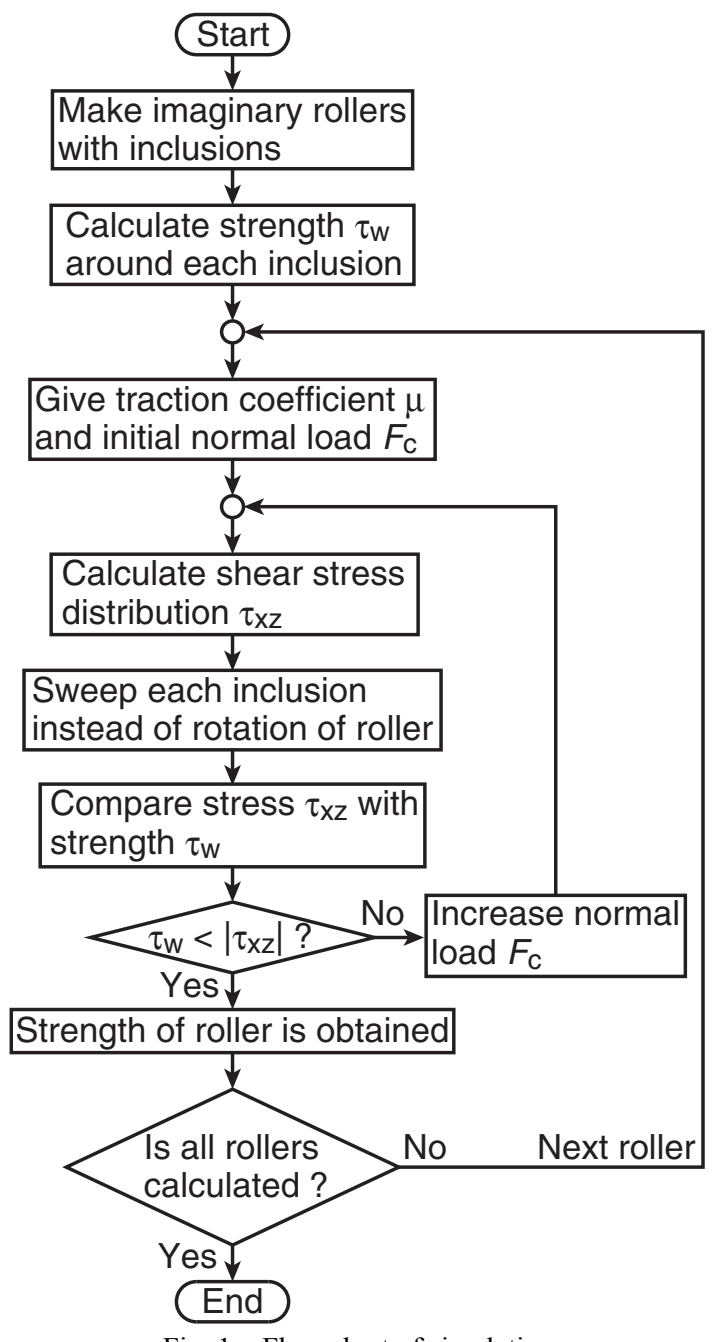

Fig. 1 Flow chart of simulation

We began by constructing the simulated roller. Inclusions were distributed throughout the interior of the roller and the locations of these were recorded in terms of depth below the roller surface $z$ and angular position $\theta$. Equation (1) was then employed to calculate the rolling contact fatigue strength in the vicinity of each inclusion. The distribution of shear stresses inside the roller due to the contact force and the traction force was then calculated. Finally, instead of rotating the roller, each inclusion was shifted toward the rolling direction in the stress distribution and the rolling contact fatigue strength $\tau_{\mathrm{w}}$, calculated in Eq. (1), was compared with $\tau_{\mathrm{xz}}$. Since the sign of $\tau_{\mathrm{xz}}$ changes about the roller contact point, $\left|\tau_{\mathrm{xz}}\right|$ was compared. Failure was assumed to occur when $\tau_{\mathrm{w}}<\left|\tau_{\mathrm{xz}}\right|$, and the fatigue strength for that case was recorded. When failure occurred from multiple inclusions, the inclusion with the lowest $\theta$ was designated as the failure initiation site. When no failure occurred, the contact force $F_{\mathrm{c}}$ was increased, the stress distribution was re-calculated, and the comparison of the fatigue strength with $\left|\tau_{\mathrm{xz}}\right|$ was repeated. This process was repeated for a given number of simulated rollers and a histogram of the fatigue strength was output. 


\subsection{Method for creation of simulated rollers}

The simulated roller is created in a given shape and assigned characteristic material properties. Here, to compare the simulation with the experimental results, the procedure for modeling the actual roller used in the experiments is described. Figure 2 shows the dimensions of the rollers employed in the experiment. The material was carburized Japan Industrial Standard (JIS) SCM415H low-alloy steel. Figure 3 presents the measured distribution of hardness in the depth direction. The effective case depth $d_{\text {eff }}$ was $0.8 \mathrm{~mm}$ and the maximum hardness $H_{2}$ was $840 \mathrm{HV}$ at depth $d_{2}=0.2 \mathrm{~mm}$. The surface hardness $H_{1}$ was $750 \mathrm{HV}$ and the core hardness $H_{3}$ was $400 \mathrm{HV}^{(12)}$. The hardness $H v$ at any depth $z$ can be approximated with the following equation ${ }^{(16)}$ :

$$
H v=\left(H_{2}-H_{3}\right) \exp \left\{-A\left(z-d_{2}\right)^{2}\right\}+H_{3}
$$

The above values were substituted for surface hardness $H_{1}$, maximum hardness $H_{2}$, core hardness $H_{3}$, depth of maximum hardness $d_{2}$, and effective case depth $d_{\text {eff. By }}$ using the relationship between depth $z$ and $d_{\text {eff }}, A$ was calculated as follows:

$$
\begin{array}{ll}
A=-\frac{1}{d_{2}^{2}} \ln \left(\frac{H_{1}-H_{3}}{H_{2}-H_{3}}\right) & \left(d \leq d_{2}\right) \\
A=-\frac{1}{\left(d_{\mathrm{eff}}-d_{2}\right)^{2}} \ln \left(\frac{550-H_{3}}{H_{2}-H_{3}}\right) & \left(d>d_{2}\right)
\end{array}
$$

The approximated curve of hardness $H v$ according to Eq. (2) is also shown in Fig.3

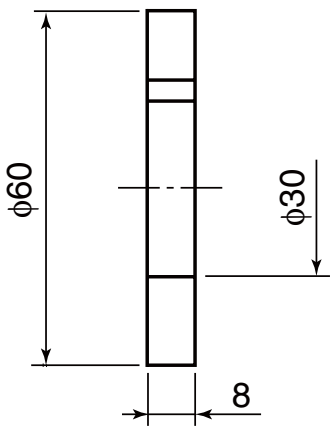

Driven roller

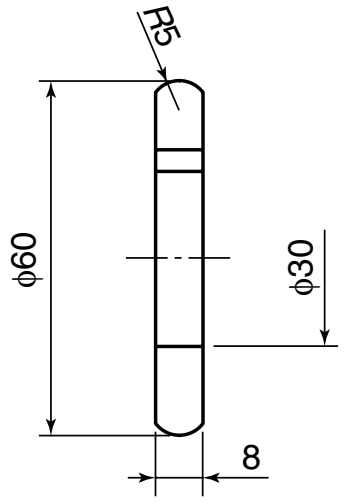

Drive roller

Fig. 2 Shape and dimension of test roller pair

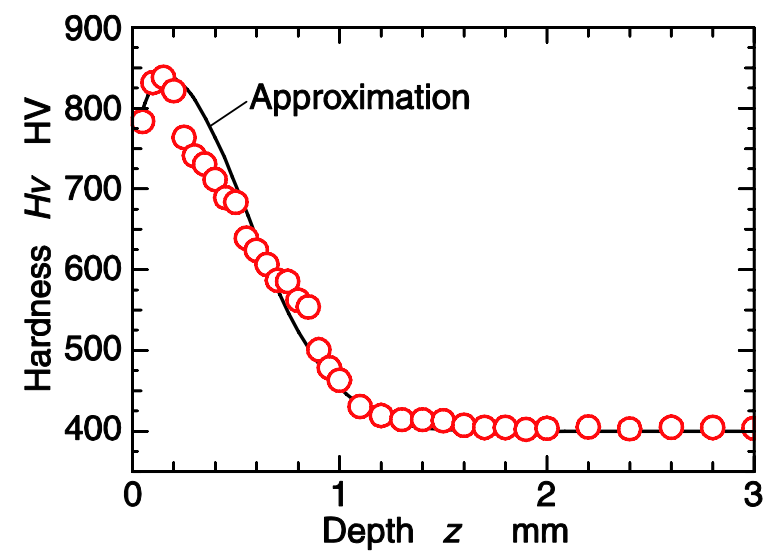

Fig. 3 Measured and approximated Vickers hardness 
Next, the dimensional distribution of the inclusions and their density in the simulated roller are set according to observations of the test specimen. Test specimen was made of pre-quenched SCM415H. The bar stock used to build the rollers was cut with a fine cutter and buffed to create the specimen. The number of inclusions and the surface area of each inclusion on the surface of the specimen were measured under a digital microscope (Keyence VH-8000, 2.11 megapixels). To increase the observed area, inclusions at least 20 $\mu \mathrm{m}^{2}$ in size were measured in 270 views at $450 \times$ magnification. Each view was $0.74 \mathrm{~mm}^{2}$ and a total of $200 \mathrm{~mm}^{2}$ of surface was examined. For higher precision, inclusions of $\leq 20$ $\mu \mathrm{m}^{2}$ were also observed at $1500 \times$ in 170 views for a total of $5 \mathrm{~mm}^{2}$. These results at $1500 \times$ were then multiplied by 40 to estimate the results for observation of $200 \mathrm{~mm}^{2}$ of area and added to the results at the $450 \times$ magnification. According to the research on SUJ2 by Hiroshi Murakami, inclusions less than $\sqrt{\text { area }}=2 \mu \mathrm{m}$ in size do not affect the fatigue life of a roller ${ }^{(17)}$; that is, such inclusions do not become the initiation sites of failure. In view of that report and the limits of precision of the digital microscope, we decided not to measure inclusions less than $1 \mu^{2}$ in size. Figure 4 is a histogram of the areas of observed inclusions. It should be noted that the greater the inclusion size, the lower the frequency of occurrence. The measurement of the largest inclusion was $\sqrt{\text { area }}=36.2 \mu \mathrm{m}$. The inclusion density was $107 / \mathrm{mm}^{2}$.

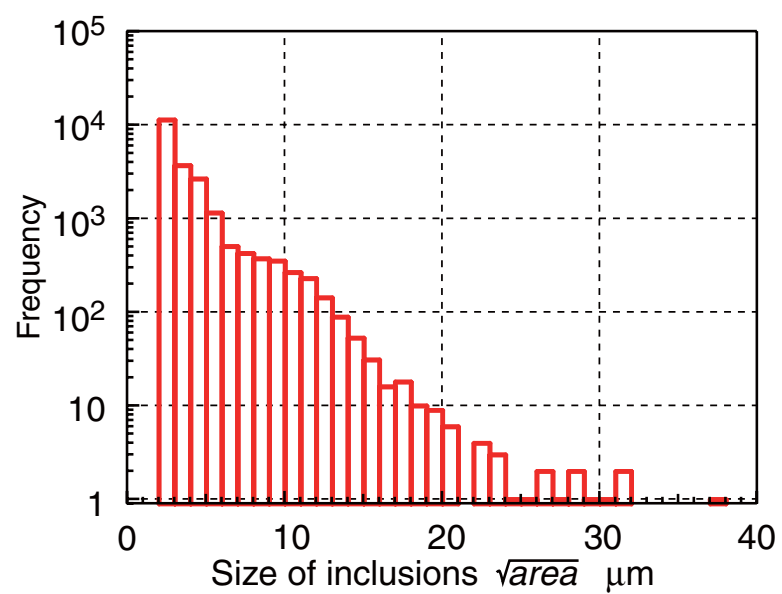

Fig. 4 Histogram of size of observed inclusions

These results were statistically examined to generate a roller model with a distribution of inclusions resembling the actual roller. Masuyama et al. reported that $\sqrt{\text { area }}$ was best represented by a composite Weibull distribution ${ }^{(15)}$. This study uses that approximation. The following equations provide the composite Weibull distribution:

$$
\begin{array}{ll}
F(t)_{1}=1-\exp \left[-\left(\frac{t}{\eta_{1}}\right)^{m_{1}}\right] & (0<\mathrm{F}(\mathrm{t})<\delta) \\
F(t)_{2}=1-\exp \left[-\left(\frac{t}{\eta_{2}}\right)^{m_{2}}\right] & (\delta \leq \mathrm{F}(\mathrm{t})<1)
\end{array}
$$

where $F(t)$ is the cumulative distribution percentage, $m$ is the shape parameter, $\eta$ is the scale parameter, and $\delta$ is the separation parameter. In this study, the Weibull random number was $t=\sqrt{\text { area }}$. Rewriting the above equations, we obtain the following: 


$$
\begin{aligned}
& Y_{1}=\ln \left(\ln \frac{1}{1-F(t)_{1}}\right)=m_{1} \ln t-m_{1} \ln \eta_{1} \\
& Y_{2}=\ln \left(\ln \frac{1}{1-F(t)_{2}}\right)=m_{2} \ln t-m_{2} \ln \eta_{2}
\end{aligned}
$$

As can be seen from the equations, the plot of $Y$ with respect to $\ln t$ is a linear function. We can obtain $m$ and $\eta$ from the slope of the line and the intercept, respectively. The separation parameter $\delta$ in Eqs. (4) and (5) can be found by using intersection $t_{c}$ of the two above lines:

$$
t_{c}=\frac{m_{1} \ln \eta_{1}-m_{2} \ln \eta_{2}}{m_{1}-m_{2}}
$$

Figure 5 combines the Weibull plot of the measured inclusion area $\sqrt{\text { area }}$ and the linear approximations of these results obtained from Eqs. (6) and (7). Table 1 provides the Weibull parameters obtained from the linear approximations. The above densities and probabilities were applied to the inclusions in the simulated model. To obtain the reciprocal functions of Eqs. (4) and (5), we find

$$
t=\eta[-\ln (1-F(t))] \frac{1}{m}
$$

Uniform random numbers were applied in $F(t)$ over the semi-open interval $[0,1)$ to numerically obtain the Weibull random number $t=\sqrt{\text { area }}$. These random numbers were used to randomize the locations of the inclusions.

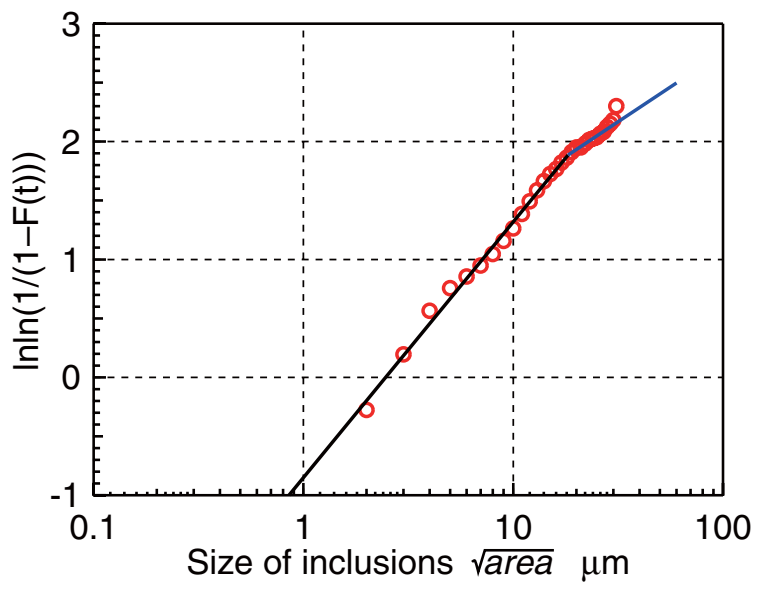

Fig. 5 Weibull plot of distribution of inclusions

Table 1 Weibull parameters

\begin{tabular}{l|l}
\hline Weibull parameter $m_{1}$ & 0.942 \\
\hline Weibull parameter $m_{2}$ & 0.514 \\
\hline Weibull parameter $\eta_{1}$ & 2.467 \\
\hline Weibull parameter $\eta_{2}$ & 0.467 \\
\hline Boundary $t_{c}$ & 18.28 \\
\hline Density of inclusions $[/ \mathrm{mm} 2]$ & 107 \\
\hline
\end{tabular}




\subsection{Estimating maximum inclusion area and lower limit of rolling contact fatigue} strength with statistics of extremes

Masuyama et al. reported that some huge inclusions were generated when they generated many amount of inclusions by applying uniform random numbers to find the Weibull random number $t=\sqrt{\text { area }}$, and thus they underestimated the fatigue $\operatorname{limit}^{(15)}$. Murakami suggested a way around this, however. He showed the statistics of extremes for predicting the lower limit of scatter in the fatigue limit by estimating the maximum value of the inclusion area $\sqrt{\text { area }}_{\max }$ included in the material ${ }^{(11)}$. In the present study, the lower limit of rolling contact fatigue strength $\tau_{\mathrm{w}}$ was found by calculating $\sqrt{\text { area }}$ max with the statistics of extremes. It was also decided to impose an upper bound on $\sqrt{\text { area }}$ in the simulated roller to prevent the generation of inclusions having an area larger than $\sqrt{\text { area }}_{\max }$.

First, a graph was created by using the statistics of extremes, based on observations of the specimen. The reference area $S_{0}$ was determined and $\sqrt{\text { area }}$ max was recorded at each visual field. The $\sqrt{\text { area }}_{\max }$ values were then sorted in ascending order and designated as $\sqrt{\text { area }} \max , j \quad(j=1, \ldots, \mathrm{n})$. The reduced variate $y_{\mathrm{i}}$ was evaluated for each $j$ by using the following equation, and $y_{\mathrm{i}}$ was plotted (as the vertical axis) with respect to $\sqrt{\text { area }}$ max :

$$
y_{i}=-\ln \left\{-\ln \left(\frac{j}{n+1}\right)\right\}
$$

Approximating these results as a linear relation, we obtain the following:

$$
\sqrt{\text { area }}_{\max }=\alpha y_{i}+\beta
$$

If $V$ is the volume to be predicted, the next return period $T$ is found with:

$$
\begin{aligned}
& T=\frac{V+V_{0}}{V_{0}} \\
& V_{0}=h S_{0}
\end{aligned}
$$

where $h$ is the virtual thickness of the solid created by extending $S_{0}$. By using $T$ in the preceding equation, $y_{\mathrm{i}}$ is found as follows:

$$
y_{i}=-\ln \left\{-\ln \left(\frac{T-1}{T}\right)\right\}
$$

These results are substituted into Eq. (11) to estimate $\sqrt{\text { area }}_{\max }$.

Figure 6 is a graph of the analysis results of the experimental specimen by the statistics of extremes. The specimen used to create this graph was the same one used to determine the distribution of inclusion sizes, as described in the previous section. The magnification was $450 \times, 270$ visual fields $n$ were observed, and the reference area $S_{0}$ was $0.74 \mathrm{~mm}^{2}$. The virtual thickness $h$ was set at the mean value, $1.28 \times 10^{-5} \mathrm{~mm}$, for $\sqrt{\text { area }}_{\max }$ in the visual fields. Thus, we obtained $V_{0}=9.46 \times 10^{-6} \mathrm{~mm}^{3}$. The critical volume $V$ we are attempting to predict must be in a portion of the roller subject to high stresses so that this portion is likely to become a failure initiation site ${ }^{(11)}$. The Lundberg-Palmgren theory for bearing life ${ }^{(8)}$ uses a hollow cylindrical critical volume $V$ whose height is $2 a$, which is the width of the Hertzian contact patch, and whose hollow circular base extends from the roller surface to depth $z_{0}$, 
where the shear stress $\tau_{\mathrm{xz}}$ reaches the maximum. This theory does not consider regions at greater depths than $z_{0}$. However, $\tau_{\mathrm{xz}}$ is a high value at depths greater than $z_{0}$. Therefore, it is possible that the theory underestimates the critical volume. Unigame et al. considered cylindrical $V$, whose height is $2 a$ and whose hollow circular base extends from the roller surface past the depth of maximum $\tau_{\mathrm{xz}}$ to the depth where the shear stress falls to $90 \%$ of the maximum $\tau_{\mathrm{xz}}{ }^{(18)}$. The maximum shear stress occurred in the interior of the material, and the stress at the material surface was lower than the maximum. Ionnides et al. defined $V$ as the locations where the stress exceeds some threshold value ${ }^{(10)}$. That method is adopted in this study. As Fig. 7 shows, the threshold is assumed to be $90 \%$ of the maximum shear stress $\tau_{\mathrm{xz} \text { max }}$. The location where the stress exceeds this threshold becomes the hollow circular disk, as shown in Fig. 7, and the critical volume $V$ becomes the hollow cylinder of height $2 a$.

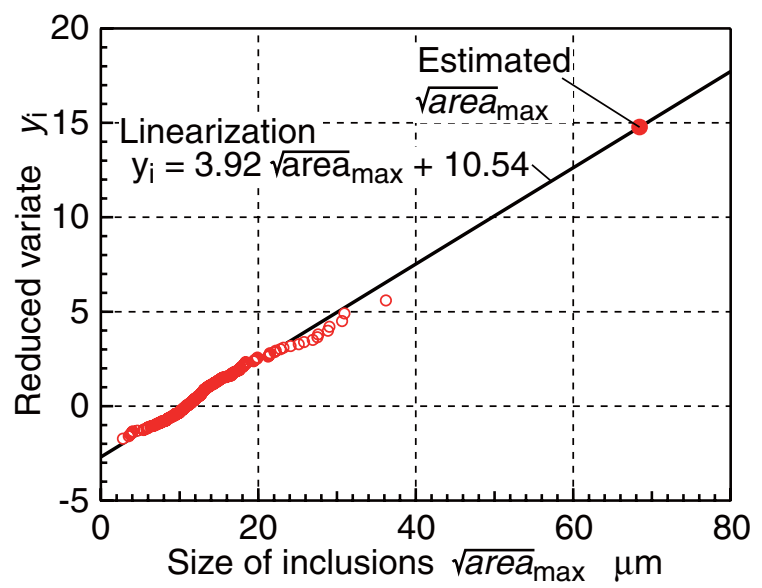

Fig. 6 Results of statistics of extremes

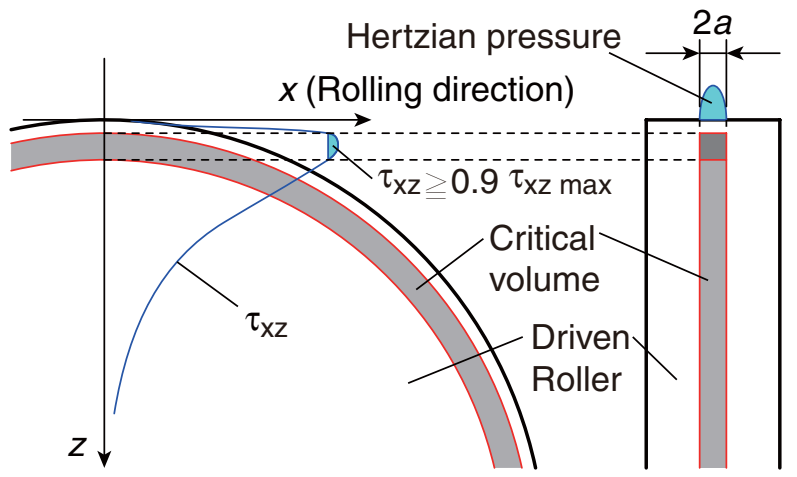

Fig. 7 Schematic of critical volume

The range of depth $z$ for $\tau_{\mathrm{xz}}=90 \%$ of $\tau_{\mathrm{xz} \max }$ under the contact force of $F_{\mathrm{c}}=1800 \mathrm{~N}$ (maximum Hertzian pressure 4.06 GPa), which corresponds to the fatigue strength found in an experiment, was calculated by the numerical solver TED/CPA (TriboLogics Corporation) by the boundary element method ${ }^{(19)}$. This depth was 0.07 to $0.28 \mathrm{~mm}, 2 a$ was $0.64 \mathrm{~mm}$, and $V$ was $24.6 \mathrm{~mm}^{3}$. The above values were inserted into Eqs. (10) through (14) and the maximum inclusion areas $\sqrt{\text { area }}_{\max }$ were estimated, and the values of $\alpha=3.92, \beta=$ $10.54, y_{\mathrm{i}}=14.8$, and $\sqrt{\text { area }}_{\max }=68.4 \mu \mathrm{m}$ were obtained from Eq. (11). This result was $89 \%$ larger than the observed maximum $\sqrt{\text { area }}=36.2 \mu \mathrm{m}$. Though, the expansion of observed area may result in the finding of such a large inclusion. Due to these results, inclusions generated in the simulation whose $\sqrt{\text { area }}$ exceeded $69 \mu \mathrm{m}$ were excluded. Also, the lower limit of rolling contact fatigue strength $\tau_{\mathrm{w}}$ was evaluated using Eq. (1) when inclusions with $\sqrt{\text { area }}_{\max }=69 \mu \mathrm{m}$ were present in the above critical volume. This lower limit was found to be $688 \mathrm{MPa}$. 


\subsection{Calculation of shear stress distribution in interior of roller under a traction force}

The shear stress $\tau_{\mathrm{xz}}$, which is in the interior of the roller and compared with rolling fatigue strength $\tau_{\mathrm{w}}$, was calculated by using the boundary element method software $\mathrm{TED} / \mathrm{CPA}^{(19)}$. In Hertzian contact, extremely high stresses are generated in the vicinity of the contact patch. To reduce computation time, the inclusions for which calculations were performed were limited to those within $2 \mathrm{~mm}$ of depth from the surface of the simulated roller. The limits of the calculation were $0 \leq z \leq 2 \mathrm{~mm}$ in the depth direction and $-5 \leq x \leq+5$ $\mathrm{mm}$ in the rolling direction, with the coordinate origin at the point of contact. The $x$ coordinate was positive in the rolling direction. TED/CPA ${ }^{(19)}$ is capable of calculating internal stresses in the roller due to friction at the surface. Figure 8 presents an example of the calculations when the traction coefficient was $\mu=0.12$, the same as that used in the experiment $^{(12)}$. The roller dimensions were identical to those of the driven roller shown in Fig. 2. The values of Young's modulus $=207.5 \mathrm{GPa}$, Poisson's ratio $=0.3$, and contact force $F_{\mathrm{c}}=1800 \mathrm{~N}$ were employed in the calculations. The scale of the vertical axis in the figure is double that of the horizontal axis. The distribution of $\tau_{\mathrm{xz}}$ was symmetric about $x=0$ under frictionless contact. As seen in the figure, the presence of the traction forces increases $\tau_{\mathrm{xz}}$ in the positive $x$ region. In this region, $\tau_{\mathrm{xz} \max }$ was $790 \mathrm{MPa}$, while it was $41 \%$ higher at 560 $\mathrm{MPa}$ in the negative $x$ region. Figure 9 is a graph of $\tau_{\mathrm{xz} \max }$ as the traction coefficient $\mu$ was varied from zero to 0.2 under constant $F_{\mathrm{c}}=1800 \mathrm{~N}$. We see that $\tau_{\mathrm{xz} \text { max }}$ increased with $\mu$, as it was $30 \%$ higher at $\mu=0.2$ than at $\mu=0$.

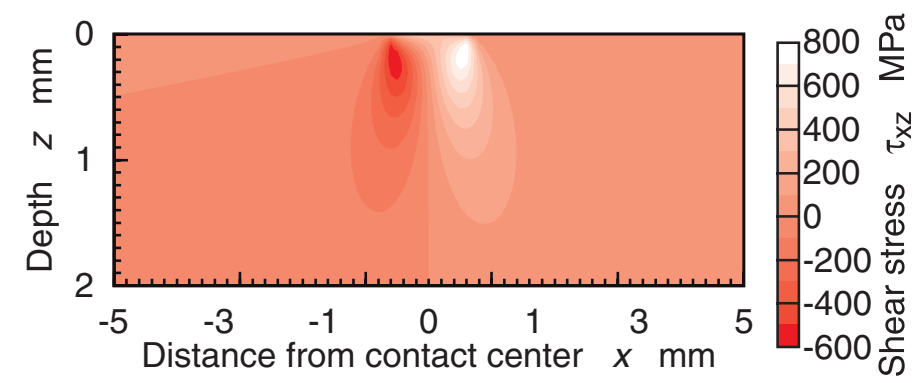

Fig. 8 Distribution of shear stress $\tau_{\mathrm{xz}}$ of driven roller $\left(F_{\mathrm{c}}=1800 \mathrm{~N}\right)$

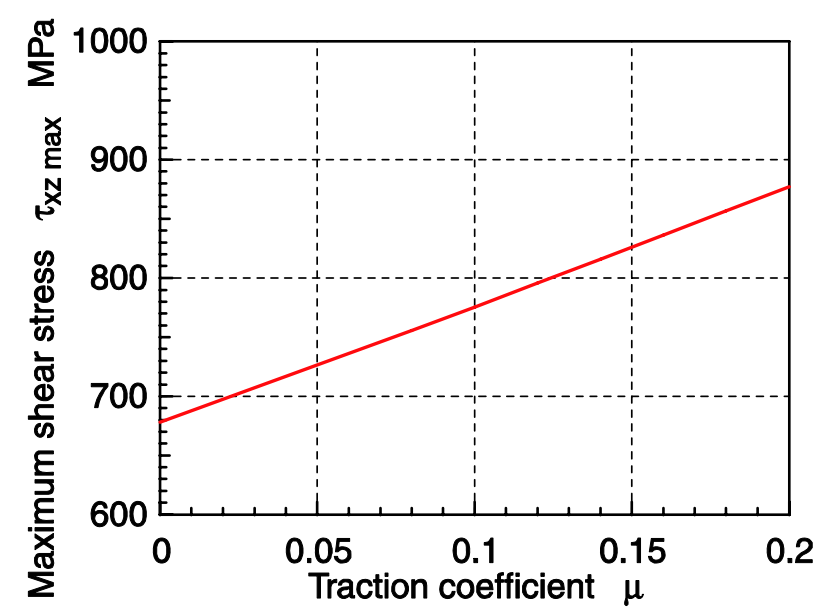

Fig. 9 Relationship between traction coefficient $\mu$ and maximum shear stress $\tau_{\mathrm{xz} \max }\left(F_{\mathrm{c}}=1800 \mathrm{~N}\right)$

\section{Simulation Results}

The rolling contact fatigue strength of a traction drive element was simulated and those results were compared with the results of an experiment. One hundred simulated rollers were created and each roller was assigned approximately 14,000 inclusions. Six of the rollers were each assigned one inclusion whose area index $\sqrt{\text { area }}$ exceeded $69 \mu \mathrm{m}$ in the 
analysis of the specimen by the statistics of extremes. As described in 3.3, those inclusions were excluded from the calculations.

Figure 10 presents the results of the simulation of rolling contact fatigue strength $\tau_{\mathrm{w}}$ when the traction coefficient $\mu$ was 0.12 , the same value as that in the experiment ${ }^{(12)}$. Here, $\tau_{\mathrm{w}}$ was distributed between 710 and $892 \mathrm{MPa}$ with a standard deviation $\sigma=39.2 \mathrm{MPa}$. Figure 11 is a normal probability plot of the results. The figure shows these points in a linear curve, thus indicating that the results of the simulation approximately obey a normal distribution. The rolling contact fatigue strength resulting in a failure rate of $50 \%$ was calculated at $810 \mathrm{MPa}$. Comparing that result with the experimentally determined value of $\tau_{\mathrm{w}}=790 \mathrm{MPa}^{(12)}$, we find an error of $2.5 \%$. The simulation successfully reproduced the process of finding the mean value of strength in a fatigue test of a large number of specimens. The scatter in the experimental results for fatigue strength was not obtained, because the number of specimens was too low; therefore, no meaningful comparison of the scatter could be made.

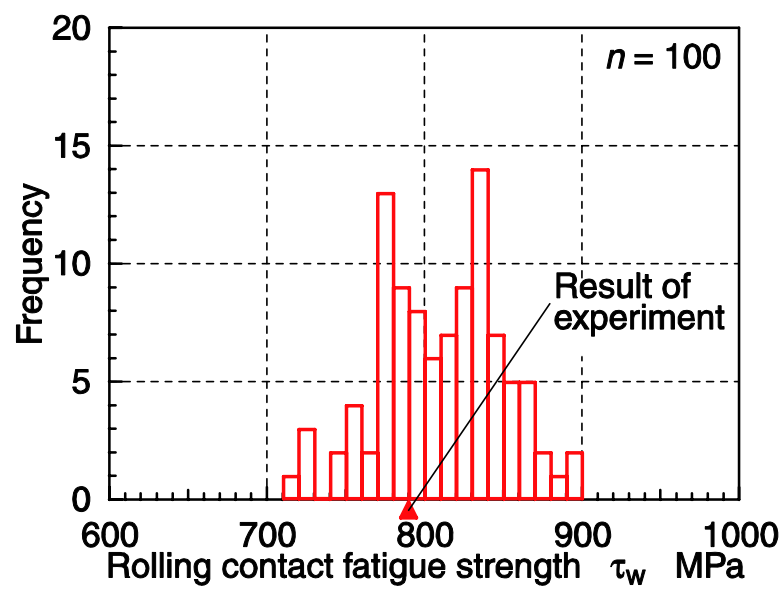

Fig. 10 Estimated rolling contact fatigue strength

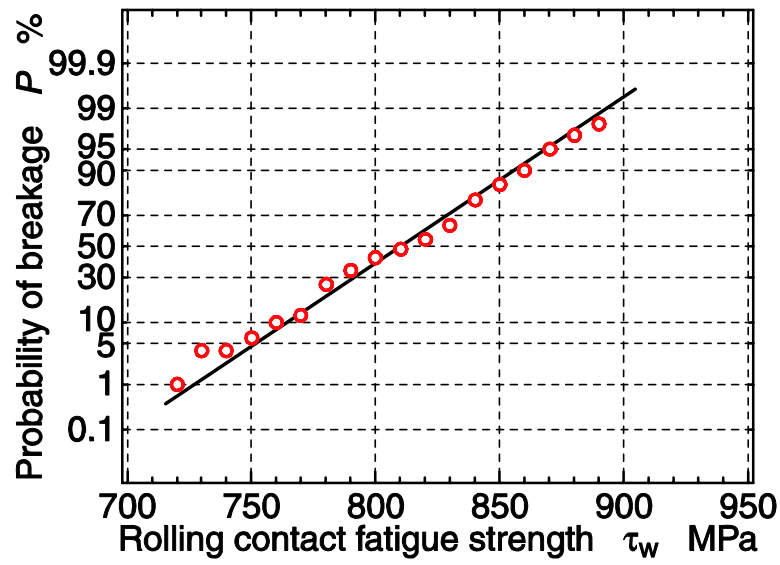

Fig. 11 Normal probability plot of estimated rolling contact fatigue strength

Figure 12 is a histogram of $\sqrt{\text { area }}$ of the inclusions that were failure initiation sites. In this figure, $\sqrt{\text { area }}$ was distributed between 18.0 and $65.8 \mu \mathrm{m}$ and the most commonly appearing values were around $25 \mu \mathrm{m}$. Few sites showed $\sqrt{\text { area }}$ greater than $50 \mu \mathrm{m}$. The scatter of the rolling contact fatigue strength in Fig. 10 occurred because $\sqrt{\text { area }}$ showed this kind of distribution. Figure 13 presents the distribution of $\tau_{\mathrm{xz}}$ under simulated mean contact force $F_{\mathrm{c}}=1950 \mathrm{~N}$ during failure and the failure initiation sites. The reader can see that failure is concentrated in locations where $\tau_{\mathrm{xz}}$ reached a maximum. Figure 14 is a histogram of the depths of the failure initiation sites in combination with the distribution of $\tau_{\mathrm{xz}}$ when $F_{\mathrm{c}}=1950 \mathrm{~N}$. The graphed values of $\tau_{\mathrm{xz}}$ are those appearing at $x=0.575 \mathrm{~mm}$, 


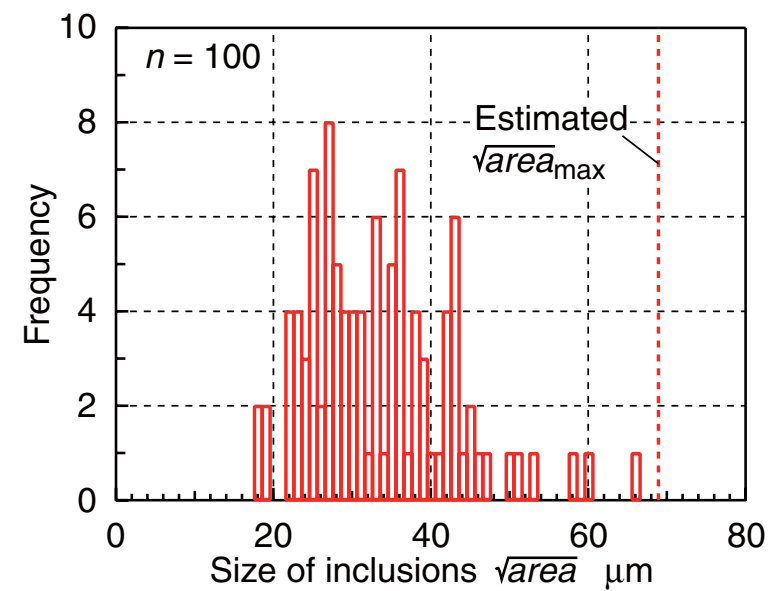

Fig. 12 Histogram of size of failure initiation sites

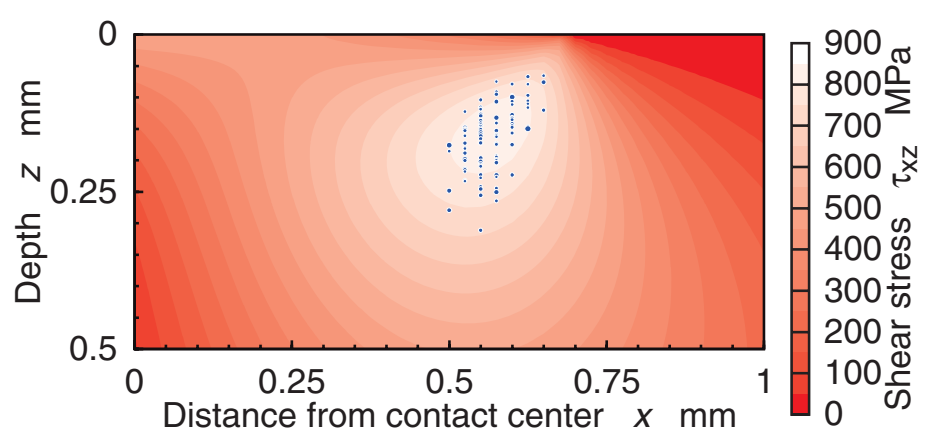

Fig. 13 Distribution of shear stress $\tau_{\mathrm{xz}}\left(F_{\mathrm{c}}=1950 \mathrm{~N}\right)$ and failure initiation sites

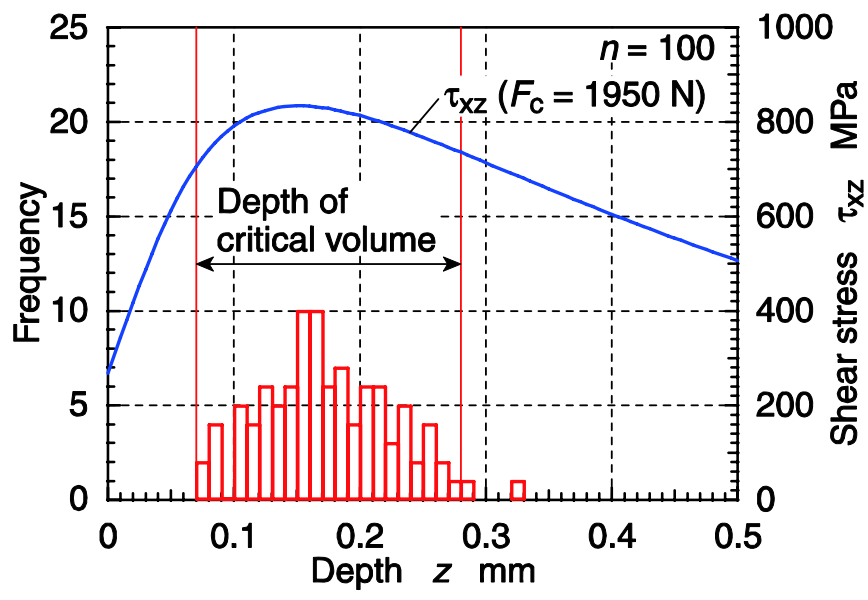

Fig. 14 Histogram of depth of failure initiation sites

where $\tau_{\mathrm{xz} \max }$ occurred. The depth of failure initiation $z$ was in the range 0.07 to $0.31 \mathrm{~mm}$. These results match quite well with the range of depths for critical volume $V$ given in 3.3. Figure 15 is a histogram of the $x$ values of the initiation site of failure. These sites were centered around $0.575 \mathrm{~mm}$, where the maximum shear stress was observed. The range of these values was 0.50 to $0.65 \mathrm{~mm}$. None of the roller models exhibited failure initiation sites in the $x<0$ region. This was because the shear stresses are increased in the positive $x$ region by the traction forces operating on the roller surface.

Next, the rollers whose inclusions were exactly the same as above were employed in simulations with $\mu=0$ and $\mu=0.06$. The rolling contact fatigue strength distribution was nearly identical to that when $\mu=0.12$, and the means and standard deviations were exactly identical for each value of $\mu$. From Eq. (1), if the size of an inclusion in the simulated roller is the same as its depth, the strength of the roller is unaffected. This explains the above results. Nevertheless, as $\mu$ takes different values, the contact force capable of causing failure 


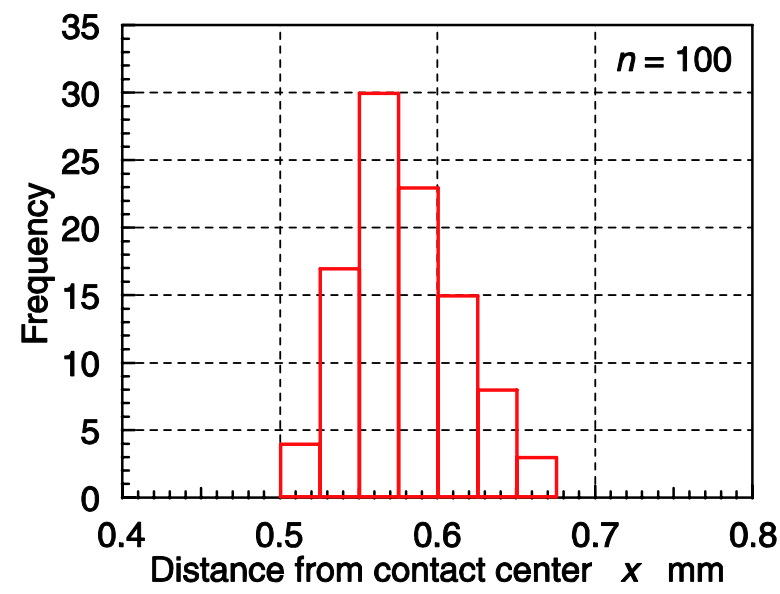

Fig. 15 Histogram of distance from contact center of failure initiation sites

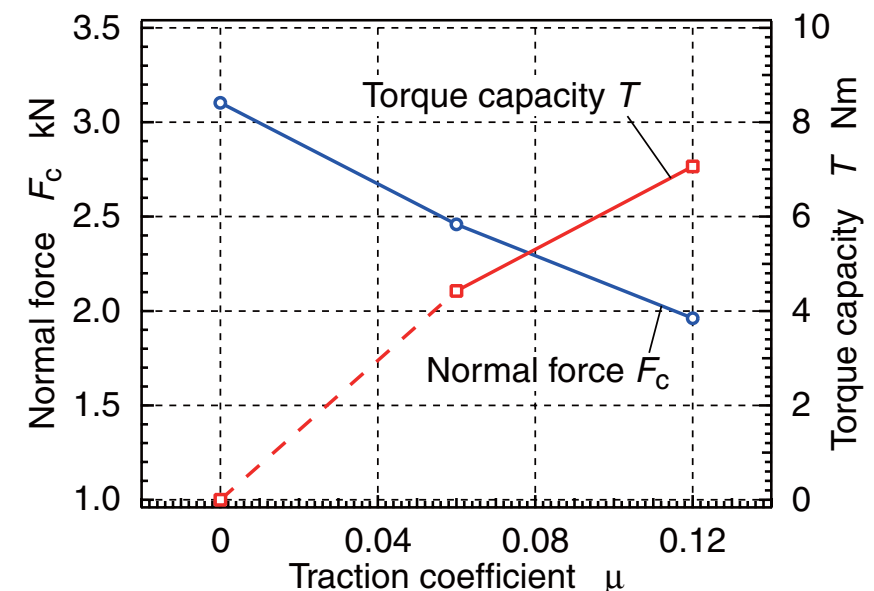

Fig. 16 Mean contact force $F_{\mathrm{c}}$ of occasion of failure and torque capacity $T$

also varies. Figure 16 shows how the mean contact force $F_{\mathrm{c}}$ during failure varies with $\mu$. As shown, $F_{\mathrm{c}}$ falls as $\mu$ increases. This is because $\tau_{\mathrm{xz}}$ is increased by the presence of traction force and reaches $\tau_{\mathrm{w}}$, regardless of low values of $F_{\mathrm{c}}$. The figure also provides the values of torque capacity $T$ corresponding to $F_{\mathrm{c}}$. $T$ was found by multiplying $F_{\mathrm{c}}$ by $\mu$ and the radius of $30 \mathrm{~mm}$ of the experimental roller shown in Fig. 2. $T$ increases with $\mu$; therefore, the torque capacity is higher at high values of $\mu$, regardless of the rolling contact fatigue strength.

\section{Summary}

A simulation of the rolling contact fatigue strength of a traction drive element was proposed. The simulation can account for both the distribution of sizes of inclusions in the element material and the influence of traction forces at the element surface. The following results were obtained.

1) The shear strength of the matrix structure surrounding an inclusion was estimated with an equation, and a simulation of the rolling contact fatigue strength in a traction drive element was proposed to compare that strength with the distribution of stresses in a roller affected by traction forces.

2) The hardness distribution and the Weibull distribution of inclusion dimensions, which were necessary parameters for the prediction equation to calculate the value of the rolling contact fatigue strength, were determined by observation of an actual test specimen.

3) A simulation assuming the same traction coefficient as that in the experiment predicted a rolling contact fatigue strength of $810 \mathrm{MPa}$ with a standard deviation of $39.2 \mathrm{MPa}$, which differed from the experimental value by only $2.5 \%$. 
4) Simulations of the rolling contact fatigue strength were then carried out by using the same roller model while varying the traction coefficient. The contact force resulting in failure was observed to fall as the traction coefficient increased and the torque capacity increased. Thus, the torque capacity increases with the traction coefficient, regardless of changes in the rolling contact fatigue strength.

\section{Appendix Experimental Determination of Coefficient $c^{(12)}$}

To find the value of $c$ in Eq. (1), it is necessary to know the size and location of the inclusion that gave rise to the failure in the experiment. However, this is quite difficult, due to the challenge of identifying the actual site of the origin of failure and the potential for actual inclusions to disappear from the material during crack propagation or during surface flaking. Therefore, artificial defects with controlled dimensions were introduced into a roller and the rolling contact fatigue test was conducted, based on the results of the experiments of Endo ${ }^{(20)}$ and Fujii ${ }^{(21)}$.

Figure 2 shows the pair of rollers employed in the experiment. The ellipticity parameter $k(=a / b)$ was 0.51 . The surface roughness of the rollers was $\leq 0.03 \mu \mathrm{mRa}$. As shown in Fig. 17, holes $5 \mathrm{~mm}$ deep and located $0.3 \mathrm{~mm}$ below the rolling contact surface were bored in the side of the driven roller one by one with electric discharge machining. The diameters of these holes were either all $120 \mu \mathrm{m}$ on the roller or all $160 \mu \mathrm{m}$ on the roller. These holes were the artificial defects. It was desirable to place the artificial defects where the shear stress $\tau_{\mathrm{xz}}$ was maximal. However, that location was approximately at $z=0.15 \mathrm{~mm}$ below the roller surface. This was too close to the surface to be reached by machining. Therefore, the artificial defect was placed at $z=0.3 \mathrm{~mm}$. As described in $\mathbf{3 . 2}$, the material of the rollers was carburized SCM415H. The measured hardness at each depth is shown in Fig. 3.

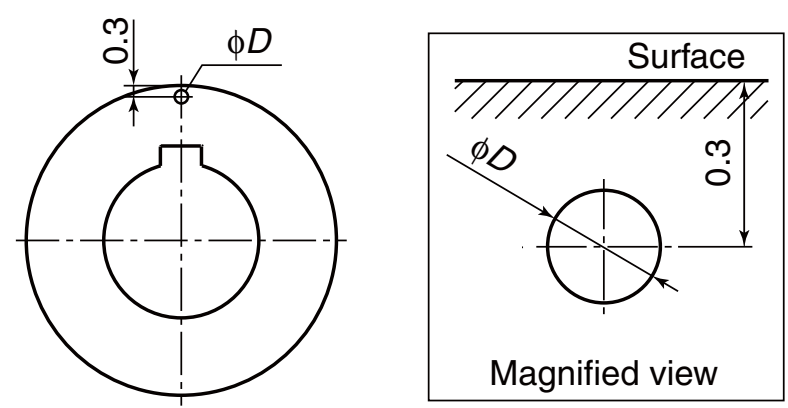

Fig. 17 Test roller containing artificial small defect

The two-roller fatigue tester shown in Fig. 18 was used for these tests. The drive roller and the driven roller were rotated by servo motors at 3000 and $2940 \mathrm{~min}^{-1}$, respectively, for a slip ratio $\mathrm{Cr}$ of 2\%. ITF32 (Idemitsu Kosan Co., Ltd.) was employed as the traction oil. Table 2 shows the properties of the traction oil. The temperature was controlled at $313 \mathrm{~K}$ and the oil was supplied to the rollers at $540 \mathrm{ml} / \mathrm{min}$. The traction coefficient $\mu$ was measured while $\mathrm{Cr}=2 \%$ on another two-disk tester, and the value of $\mu=0.12$ was found.

Figure 19 provides the results of the rolling contact fatigue test. In the TED/CPA package ${ }^{(19)}$, Young's modulus, Poisson's ratio, and the traction coefficient $\mu$ were set to $207.5 \mathrm{GPa}, 0.3$, and 0.12 , respectively, and the shear stress of the vertical axis was calculated. This software package does not provide for calculating the stress around a hole. Therefore, the influence of the stress distribution by the artificial defect was neglected. Here, it was assumed that there was no horizontal portion of the $S-N$ curve for the bearing, whose failure mode is rolling contact fatigue. Therefore, the fatigue strength $\tau_{\mathrm{w}}$ was sought at $10^{7}$ cycles, as described in Section 2.

The value of $c$ in Eq. (1) was found by experiment. As Fig. 20 shows, $\sqrt{\text { area }}$ for the 


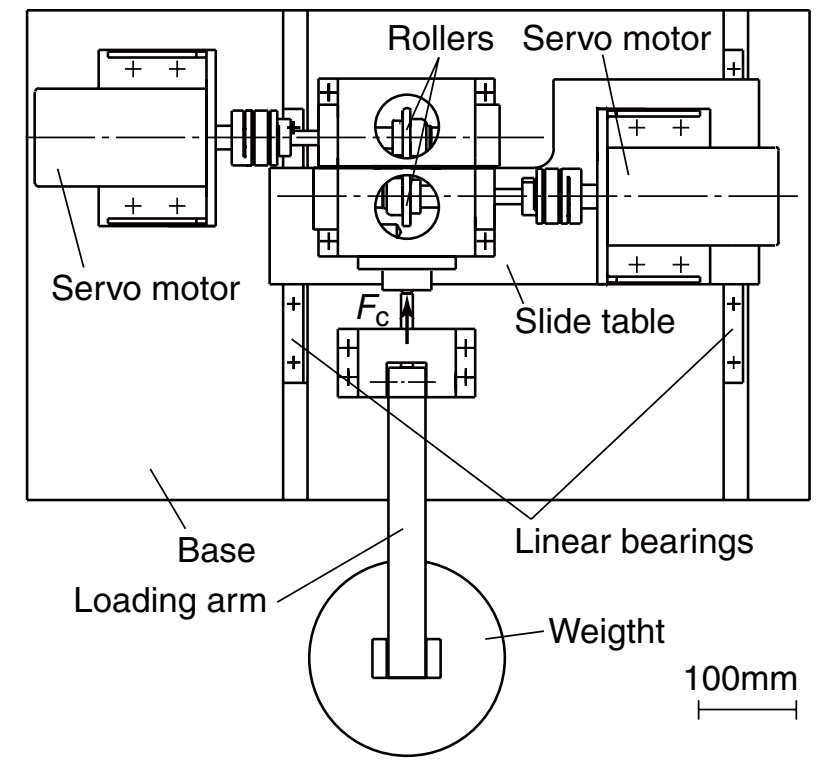

Fig. 18 Schematic of two-roller fatigue tester

Table 2 Properties of traction oil

\begin{tabular}{c|c|c|c|c|c}
\hline $\begin{array}{c}\text { Kinematic viscosity } \\
{\left[\mathrm{mm}^{2} / \mathrm{sec}\right]}\end{array}$ & $\begin{array}{c}\text { Density } \\
{\left[\mathrm{g} / \mathrm{cm}^{3}\right]}\end{array}$ & \multicolumn{3}{|c}{$\begin{array}{c}\text { Pressure viscosity } \\
\text { coefficient }\left[\mathrm{GPa}^{-1}\right]\end{array}$} \\
\hline $313 \mathrm{~K}$ & $373 \mathrm{~K}$ & $288 \mathrm{~K}$ & $303 \mathrm{~K}$ & $313 \mathrm{~K}$ & $373 \mathrm{~K}$ \\
\hline 32.83 & 5.65 & 0.96 & 28.5 & 26.1 & 16.4 \\
\hline
\end{tabular}

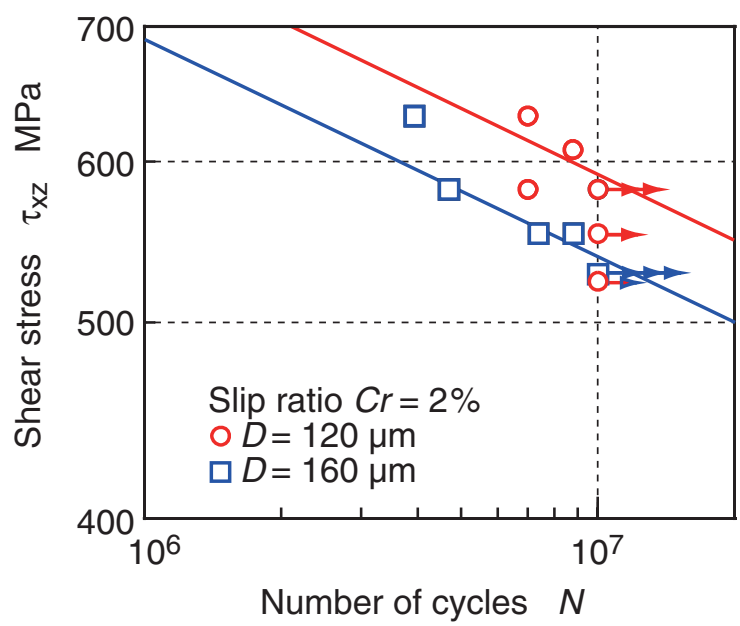

Fig. $19 S-N$ curves using rollers with artificial defects

artificial defect was defined by using the product of width $2 a$ of the Hertzian contact patch and the diameter of the defect hole. The Hertzian contact patch width $2 a$ was calculated with TED/CPA ${ }^{(19)}$ at the same time that the maximum Hertzian pressure $P_{\mathrm{H}}$ was calculated. These calculations yielded $\sqrt{\text { area }}=267 \mu \mathrm{m}$ for the $120 \mu \mathrm{m}$ diameter hole and $\sqrt{\text { area }}=$ $299 \mu \mathrm{m}$ for the $160 \mu \mathrm{m}$ hole. It was also found that, due to traction forces, $\tau_{\mathrm{xz}}$ is not uniform throughout a fully reversed cycle. Because of this, a modified Goodman's diagram was employed to correct the effect of mean stress on the evaluation stress value. The diagram indicated $c$ values of 1.01 for the $120 \mu \mathrm{m}$ hole and 0.93 for the $160 \mu \mathrm{m}$ hole. This difference was approximately $8 \%$, so these values were averaged to obtain $c=0.97$. These results are summarized in Table 3. 


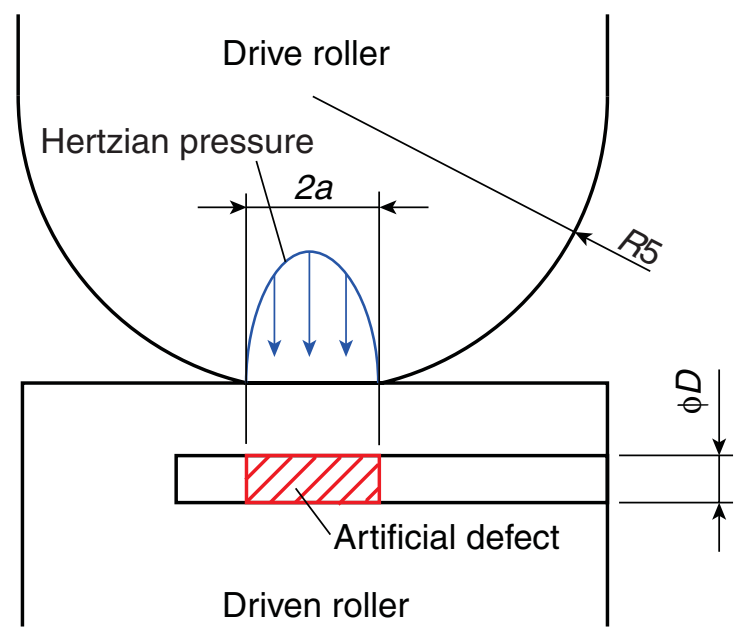

Fig. 20 Schematic of area of artificial defect

Table 3 Values used for calculating $c$

\begin{tabular}{c|c|c|c|c|c}
\hline $\begin{array}{c}D \\
{[\mu \mathrm{m}]}\end{array}$ & $\begin{array}{c}\sqrt{\text { area }} \\
{[\mu \mathrm{m}]}\end{array}$ & $\begin{array}{c}\text { Hardness } \\
{[\mathrm{HV}]}\end{array}$ & $\begin{array}{c}P_{\mathrm{H}} \\
{[\mathrm{MPa}]}\end{array}$ & $\begin{array}{c}\tau_{\mathrm{w}} \\
{[\mathrm{MPa}]}\end{array}$ & $c$ \\
\hline 120 & 267 & 830 & 3.78 & 590 & 1.01 \\
\hline 160 & 299 & 830 & 3.54 & 532 & 0.93 \\
\hline
\end{tabular}

\section{References}

(1) Machida, H., Itoh, H., Imanishi, T., Tanaka, H., Design principle of high power traction drive CVT, SAE paper, 950675, (1995).

(2) Machida, H., Hata, H., Nakano, M., Tanaka, H., Half-Toroidal Traction Drive Continuously Variable Transmission for Automobile Propulsion Systems (Traction Drive Materials, Transmission Design and Efficiency), Trans. JSME, Ser. C (in Japanese), Vol. 59, No. 560 (1993), pp. 1154-1160.

(3) Deng, G., Yamanaka, M., Yamamoto, R., Ono, N., Kato, M., Inoue, K., Contact Fatigue and Strength Evaluation of Traction Drive Rollers, Trans. JSME, Ser. C (in Japanese), Vol. 65, No. 635 (1999), pp. 2880-2885.

(4) Nakajima, A., Mawatari, T., Rolling contact fatigue life of bearing steel rollers lubricated with low viscosity traction oil, Tribology and Interface Engineering Series, Vol. 48 (2005), pp. 351-362.

(5) Matsuo, K., Saeki, S., Ooue, Y., Yoshida, A., Effect of Traction Fluid on Rolling Contact Fatigue Life of Thermally Refined Steel, Tribology Series, Vol.18 (1991), pp. 445-450.

(6) Coy, J. J., Rohn, D. A., Loewenthal, S. H., Constrained Fatigue Life Optimization of a Nasvytis Multiroller Traction Drive, Trans. ASME, Journal of Mechanical Design, Vol. 103 (1981), pp. 423-428.

(7) Rohn, D. A., Loewenthal, S. H., Coy, J. J., Simplified Fatigue Life Analysis for Traction Drive Contacts, Trans. ASME, Journal of Mechanical Design, Vol. 103 (1981), pp. 430-439.

(8) Harris, T. A., Kotzalas, M. N., Rolling Bearing Analysis, Fifth Edition, Advanced Concepts of Bearing Technology, Taylor \& Francis, (2006).

(9) Nikas, G. K., Fatigue Life and Traction Modeling of Continuously Variable Transmissions, Trans. ASME, Journal of Tribology, Vol. 124 (2002), pp. 689-698.

(10) Ioannides, E., Harris, T. A., A new fatigue life model for rolling bearings, Trans. ASME, Journal of Tribology, Vol. 107 (1985), pp. 367-378.

(11) Murakami, Y., Metal fatigue: effects of small defects and nonmetallic inclusions, Elsevier, 
(2002).

(12) Yamanaka, M., Yamamura, J., Narita, Y., Inoue, K., Evaluation of Rolling Contact Fatigue Strength for Traction-drive Elements by Using Artificial Defect, Journal of Japan Society for Design Engineering, Vol. 47, No. 5 (2012), pp. 252-258.

(13) Murakami, Y., Kodama, S., Konuma, S., Quantitative Evaluation of Effects of Nonmetallic Inclusions on Fatigue Strength of High Strength Steel, Trans. JSME, Ser. A (in Japanese), Vol. 54, No. 500 (1988), pp. 688-696.

(14) Masuyama, T., Kato, M., Inoue, K., Yamashita, T., Evaluation of Bending Strength of Carburized Gears Based on a Quantification of Defect Size in the Surface Layer, Proc. ASME DETC'00, DETC2000/PTG-14381, (2000).

(15) Masuyama, T., Asano, J., Inoue, K., Fatigue Strength Simulation of Carburized Gears based on Weibull Distribution of Inclusions, Proc. JSME (in Japanese), No. 02-12 (2002), pp. 33-36.

(16) Yamanaka, M., Kato, M., Narita, Y., Inoue, K., Evaluation of Surface Durability for Traction-drive Elements Considering Distribution of Inclusions : 1st Report, Research Plan and Simulation Proc. JSME (in Japanese), No. 08-12 (2008), pp. 97-100.

(17) Murakami, H., Estimation of Rolling Contact Fatigue Life due to Determination of Non-Metallic Inclusions, NTN Technical Review (in Japanese), No. 68 (2000), pp. 58-62.

(18) Unigame, Y., Hiraoka, K., Takasu, I., Kato, Y., Evaluation procedures of nonmetallic inclusions in steel for highly reliable bearings, Journal of ASTM International, Vol. 3, No.5 (2006), pp. 34-41.

(19) Kakoi, K., Numerical Analysis of 3-Dimensional Contact Problems with Friction by Special Boundary Element Method, Trans. JSME, Ser. A (in Japanese), Vol. 57, No. 544 (1991), pp. 3010-3015.

(20) Endo, M., Effects of Artificial Small Defect and Graphite on Torsional Fatigue Strength of Ductile Cast Iron(Special Issue on Fatigue), Journal of The Society of Materials Science (in Japanese), Vol. 45, No. 1 (1996), pp. 16-20.

(21) Fujii, M., Mizuno, Y., Yoshida, A., Influence of Artificial Defect on Rolling Contact Fatigue Strength of Steel Roller, Proc. JSME (in Japanese), No. 07-15 (2007), pp. 43-46. 